\title{
Cardiac-self efficacy predicts adverse outcomes in coronary artery disease (CAD) patients
}

\author{
Adrienne O'Neil ${ }^{1,2^{*}}$, Michael Berk ${ }^{1,3,4,5}$, Justin Davis ${ }^{1}$, Lesley Stafford ${ }^{3,6,7}$ \\ ${ }^{1}$ School of Medicine, Deakin University, School of Medicine and Barwon Health, Geelong, Australia; \\ *Corresponding Author: AONEIL@barwonhealth.org.au \\ ${ }^{2}$ School of Public Health and Preventive Medicine, Monash University, Melbourne, Australia \\ ${ }^{3}$ Department of Psychiatry, University of Melbourne, Parkville, Australia \\ ${ }^{4}$ Florey Institute of Neuroscience and Mental Health, Parkville, Australia \\ ${ }^{5}$ Orygen Youth Health Research Centre, Parkville, Australia \\ ${ }^{6}$ Centre for Women's Mental Health, Royal Women's Hospital, Parkville, Australia \\ ${ }^{7}$ School of Psychological Sciences, University of Melbourne, Parkville, Australia
}

Received 10 May 2013; revised 10 June 2013; accepted 30 June 2013

Copyright (C 2013 Adrienne O’Neil et al. This is an open access article distributed under the Creative Commons Attribution License, which permits unrestricted use, distribution, and reproduction in any medium, provided the original work is properly cited.

\begin{abstract}
Background: Little is known about the predictive role of Cardiac Self Efficacy (CSE) in the ensuing months following a coronary event. We sought to determine whether CSE predicts adverse events in the months following discharge in patients with Coronary Artery Disease (CAD). Design: Data from a prospective study of 193 patients recently hospitalized for CAD. Methods: Data were collected via participant self-report and medical records at 3-month post-discharge (baseline; T1), 6-month post-discharge (T2) and 9-month post-discharge (T3). CSE was measured using the Cardiac Self Efficacy Scale. Multi-variate regression modeling was applied to explore the association between baseline CSE scores and cardiac-related hospital admissions and functional cardiac status at T2 and T3. Other outcomes included any hospital admissions, self-reported mental and physical health at follow up. Results: Higher CSE scores at baseline significantly predicted better cardiac functioning and self-rated mental and physical health at both T2 and T3 (with one exception); this was consistent across all five models. While baseline CSE did not predict cardiac or other hospital admission at T2, CSE was a significant predictor of both outcomes at T3; higher CSE scores resulted in reductions in likelihood of hospital admissions. After adjustment for psychosocial variables however, neither association remained. Baseline depression explained the association between baseline CSE and any cardiac admis-
\end{abstract}

sions, as well as baseline CSE and any hospital admissions at T3 follow up. Conclusions: While CSE can predict key outcomes following a CAD event, much of the association can be explained by the presence of depression.

Keywords: Self-Efficacy; Cardiac; Coronary Artery Disease (CAD); Depression; Functioning

\section{INTRODUCTION}

Self efficacy is a psychological construct which describes how one's subjective belief in their ability to perform a task in a desired manner affects their physical engagement and subsequent completion of that task [1, 2]. It follows that Cardiac Self Efficacy (CSE) is a cardiac-specific measure of a person's belief in their ability to perform activities which relate to the symptoms and challenges imposed by their cardiovascular disease (CVD) [3]. CSE motivates individuals to make healthy lifestyle choices in regards to their CVD by creating a desire and willingness to adopt such behaviours [4]. Self efficacy has been shown to affect health-related behaviours and health-related outcomes in the management of chronic disease patients [5], and is a very strong predictor of behavioural modification amongst patients of any age and state of health [6]. Measurements of self efficacy in CVD have been demonstrated to be better predictors of outcomes including the use of analgesia, physical activity, and return to work than other variables such as age or medical status [3]. Following an acute coronary event, patients are suddenly confronted with a number of difficult challenges and questions, including the imposition of lifestyle changes, the future management of any recur- 
ring chest pain and uncertainty about their health status in the future [7]. CSE is particularly important in these patients as the idea of cardiac self management can often be foreign to many patients who have previously expected that their conditions would be solely managed by their physicians, and indeed may be linked to the person seeing their own past behaviours as causative, leading to denial or other maladaptive behaviours [8].

A patient's CSE has been shown to directly influence their level of commitment, effort, and perseverance towards making suggested lifestyle changes [9]. Patients perceptions' of their illness and the expectations of their roles in the management of their conditions can often differ from those held by their healthcare providers [10]. Patients who feel powerless due to the effects of their illness, or who have previously expected healthcare providers to provide the majority of care may be shown to have worse CSE, are more likely to develop poorer coping strategies, and are less likely to make significant changes to their lifestyles following an acute coronary event [11]. Amongst patients with CVD, an individual's attitude towards maintaining a normal level of function and their ability to control symptoms predicts their ability to adhere to diet and exercise regimes in the long term rehabilitation of their illness [12]. A person's confidence in their ability to make changes to their lifestyle, coupled with their perception of barriers to these changes, can significantly impact their ability to adhere to a management plan [13]. As the management of CVD is a chronic process, patients who have self confidences in their abilities to manage their illness are more likely to make beneficial changes and are more likely to experience better long term health outcomes [14]. Studies amongst patients who enter cardiac rehabilitation programs following acute coronary events have demonstrated that a patient's sense of self efficacy in relation to returning to physical exercise improves after their participations in such rehabilitation programs, and portends a better prognosis [15]. Furthermore, the likelihood of patients engaging in programs which employ physical exercise is determined more by their own CSE than it is any objective measures of exercise tolerance [10].

Previous studies have also shown that patients with a low sense of self efficacy are more likely to have worse health outcomes [12]. Analyses of data from the Heart and Soul study, comprising patients with heart failure (HF), have shown that those with low self efficacy perform worse on four health outcomes of disease specific and general health domains, including a greater symptom burden, greater physical limitation, a worse quality of life and worse overall health $[5,16]$. Reduced self efficacy has also been linked to the development of mood disturbances amongst patients with CVD [14,17] which may occur in $15 \%$ - $20 \%$ of patients with coronary artery disease (CAD) [18]. Given that CSE is at least as impor- tant as cardiac function in the determination of health in patients with CAD, it is crucial to study its effects on the outcomes of patients following an acute coronary event [16]. Previous studies that have looked at CSE and its role in the outcomes of patients with CVD have mostly done so in the context of adherence to physical activity and motivation for behavioural change within patients enrolled in cardiac rehabilitation programs. Those that have looked specifically at CSE and its outcomes in CVD have either been cross-sectional in design [16], or prospective studies amongst patients with HF [5]. These studies have shown an association between CSE and clinical outcomes independent of depressive symptoms. Whilst the Heart and Soul study concluded that CSE may be a proxy measure of clinical outcomes in HF patients over a four year period, little is known about the predictive role of CSE on such outcomes in the ensuing months following a life threatening coronary event.

This study aimed to determine whether CSE predicted subsequent cardiac-related (hospital admissions, functional cardiac status), and general adverse outcomes (any hospital admissions), in the months following a cardiac event.

\section{METHODS}

\subsection{Participants}

Study details have been reported previously [19]. Briefly, participants were recruited from a major metropolitan hospital in regional Australia between May 2005 and 2006 after admission for percutaneous transluminal coronary angioplasty (PTCA), myocardial infarction (MI), or coronary artery bypass graft surgery (CABG). This catchment area has been shown to be representative of the broader Australian community [20]. Inclusion criteria included: proficiency in English, permanently residing in Australia and provision of informed consent. Patients with diagnoses of PTCA, MI and CABG were regarded as homogenous based on evidence of similar prognostic effects for both cardiac [21] and self-rated health [22] outcomes. Patients were initially contacted via postal invitation and subsequently followed up via telephone, six weeks post-discharge. All participants provided written informed consent. Ethical approval was obtained from the relevant institutional review committees.

\subsection{Procedure}

Self-report questionnaires were posted to participants at baseline (T1; three months post-discharge), six months post-discharge (T2) and nine months post-discharge (T3). This time frame was chosen to minimise potential confounding effects of illness and stress associated with a cardiac related admission. The research team (LS) fol- 
lowed up with participants via telephone after each mail out. Participants' demographic and clinical variables were obtained from hospital medical records. Table 1 contains details of the instruments used to measure each variable and the time-point at which data were available.

Table 1. Summary of variables measured by time of measurement.

\begin{tabular}{|c|c|c|c|c|}
\hline Variable $^{\mathrm{a}}$ & Measure & \multicolumn{3}{|c|}{ Time of measurement ${ }^{\mathrm{c}}$} \\
\hline & & Time 1 & Time 2 & Time 3 \\
\hline \multicolumn{5}{|c|}{ Demographic } \\
\hline Age & Self report & $\checkmark(\mathrm{R})^{\mathrm{b}}$ & & \\
\hline Gender & Self report & $\checkmark$ & & \\
\hline Marital status & Self report & $\checkmark$ & & \\
\hline $\begin{array}{l}\text { Years of formal } \\
\text { education }\end{array}$ & Self report & $\checkmark$ & & \\
\hline $\begin{array}{l}\text { Annual Household } \\
\text { Income (\$) }\end{array}$ & Self report & $\checkmark$ & & \\
\hline \multicolumn{5}{|c|}{ Clinical } \\
\hline BMI & $\begin{array}{l}\text { Self report height } \\
\text { and weight }\left(\mathrm{kg} / \mathrm{m}^{2}\right)\end{array}$ & $\checkmark(\mathrm{R})$ & & \\
\hline Disease severity (LVEF) & Medical Records & $\checkmark(\mathrm{R})$ & & \\
\hline $\begin{array}{c}\text { Functional Cardiac } \\
\text { Status }\end{array}$ & Self report & $\checkmark$ & $\checkmark$ & $\checkmark$ \\
\hline Medical co-morbidities & Medical Records & $\checkmark$ & & \\
\hline Medications & Medical Records & $\checkmark$ & & \\
\hline $\begin{array}{l}\text { Family history of } \\
\text { coronary disease }\end{array}$ & Medical Records & $\checkmark$ & & \\
\hline Tobacco & Self-report & $\checkmark(\mathrm{R})$ & & \\
\hline Alcohol & Self-report & $\checkmark(\mathrm{R})$ & & \\
\hline $\begin{array}{c}\text { Cardiac-related } \\
\text { hospital admissions }\end{array}$ & $\begin{array}{l}\text { Self-report and } \\
\text { medical records }\end{array}$ & $\checkmark$ & $\checkmark$ & $\checkmark$ \\
\hline $\begin{array}{l}\text { Any hospital } \\
\text { admission }\end{array}$ & $\begin{array}{l}\text { Self-report and } \\
\text { medical records }\end{array}$ & $\checkmark$ & $\checkmark$ & $\checkmark$ \\
\hline $\begin{array}{c}\text { Number of diseased } \\
\text { arteries }\end{array}$ & Medical records & $\checkmark$ & & \\
\hline \multicolumn{5}{|c|}{ Psychosocial } \\
\hline $\begin{array}{l}\text { Depression and } \\
\text { anxiety (M.I.N.I.) }\end{array}$ & $\begin{array}{c}\text { Clinician } \\
\text { administered }\end{array}$ & $\checkmark$ & & \\
\hline $\begin{array}{c}\text { Depression and } \\
\text { anxiety (HADS) }\end{array}$ & Self-report & $\checkmark$ & $\checkmark$ & $\checkmark$ \\
\hline History of depression & Self-report & $\checkmark(\mathrm{R})$ & $\checkmark$ & $\checkmark$ \\
\hline HRQOL (SF-36) & Self-report & $\checkmark$ & $\checkmark$ & $\checkmark$ \\
\hline Neuroticism (IPIP-NEO) & Self-report & $\checkmark$ & & \\
\hline $\begin{array}{c}\text { Cardiac self efficacy } \\
\text { (CSES) }\end{array}$ & Self-report & $\checkmark$ & & \\
\hline $\begin{array}{c}\text { Perceived social } \\
\text { support (MSPSS) }\end{array}$ & Self-report & $\checkmark$ & & \\
\hline
\end{tabular}

Note: $b R=$ Retrospective: data collected at Time 1 but pertaining to time of index event 3 months prior. cTime $1=3$ months post-discharge; Time $2=6$ months post-discharge; Time $3=9$ months post-discharge. ${ }^{\&}$ All admissions for angina, AMI, CABG, and PTCA were grouped together and referred to as "cardiac admissions".

\subsection{Predictor}

Cardiac self efficacy was measured by the Cardiac Self Efficacy Scale (CSES) [23], a self-report inventory in which respondents are asked to rate their confidence with knowing or acting on 16 statements on a 5-point Likert-type scale. The responses are not at all confident, somewhat confident, moderately confident, very confident, and completely confident. Respondents can also rate an item as not applicable. In the original validation study [23], three items were rated as not applicable by more than $25 \%$ of respondents and were omitted from additional analysis. These items were "quit smoking if you do smoke", "lose weight if recommended to do so," and "change your diet if recommended to do so." Scores are calculated by summing the responses to each set of items and dividing by the number of rated items. Items rated as not applicable are not included in the averages. The scale used in the present study included the three items that were not analysed in the validation study. Discriminant and convergent validity were demonstrated for both scales in the validation study [23]. In terms of reliability, Cronbach alpha values for the SE-CS and SE-MF scales were reported as 0.90 and 0.87 , respectively [23]. In the present study, however, the measure was considered as a total score instead of two component subscale scores.

\subsection{Outcomes}

First, we explored cross-sectional associations between CSE and cardiac status (left ventricular ejection fraction (LVEF), days in hospital and functional cardiac status (FCS) (a measure of effort tolerance) at baseline. Next, we explored the role of baseline CSE in predicting the following outcomes at T2 and T3: 1) cardiac specific adverse events (cardiac-related hospital admissions and FCS; 2) general adverse events: any hospital admissions; and 3) self-rated mental and physical health: physical component summary (PCS) and mental component summary score (MCS), as measured by the SF-36. Hospital admissions were assessed by self-report and from participants' medical records. It was necessary to include a self-report component because participants would not necessarily attend the hospital to which they were originally admitted. Participants were asked in each of the questionnaires whether they had been admitted to hospital for any reason in the preceding three months and to specify the outcome of this admission, which were then categorized as admission for "cardiac-related" or "any" other problems.

\subsection{Co-Variates}

For the purpose of these analyses, those co-variates considered influential in the potential relationship be- 
tween CSE and health outcomes (based on the literature) were grouped (a priori) according to the following: 1) demographic variables: age, gender, education, income and marital status; 2) medical history: hypertension, diabetes mellitus, depression history and family history of CAD; 3) psychosocial characteristics: Hospital Anxiety and Depression Scale (HADS) current depressive/anxiety symptoms, current tobacco use, social support score (MSPSS; Multi-dimensional Scale of Perceived Social Support), regular alcohol use and personality type (neuroticism); 4) medication use: statin use, aspirin use; 5) cardiac function variables: LVEF, number of diseased arteries and body mass index (BMI). The association between baseline CSE and subsequent adverse events was explored in the context of these five models.

\subsection{Statistical Analyses}

Linear regression modelling was performed to assess whether CSE scores predict adverse outcomes for continuous variables (FCS, SF-36, days in hospital). Where negatively skewed (CSE scores), data were transformed using the appropriate $\log$ transformations $\left(\log _{\mathrm{e}}\right.$ transformation^3). Logistic regression was performed for all binary outcomes (e.g. ejection fraction severity, hospitalisation [yes/no]). Univariate analyses were initially conducted to explore the unadjusted relationship between the dependent and independent variables. This relationship was further explored by creating five individual models, adjusting for the aforementioned groups of variables. Measures of magnitude were presented as adjusted Coefficients and Odds Ratios (OR) with Standard Errors (SEs) and 95\% confidence intervals (CIs) for each of the five models. Stata 11 was used for all statistical analyses.

\section{RESULTS}

Of the 228 patients who were recruited, data were available for 193 participants (Figure 1). As reported previously, compared with non-participants, participants were more likely to be male, and were younger in age. Table 2 displays the key characteristics of the sample at baseline; comprising majority male $(81 \%)$ and married $(76 \%)$ participants with a mean age of 64.14 years. From a clinical perspective, $6 \%$ of participants $(n=11)$ had a LVEF $<30 \%, 21 \%(\mathrm{n}=40)$ of participants reported consuming alcohol in excess of the amount recommended by the National Heart Foundation and 14\% of participants $(n=27)$ were smokers. One third of participants $(n=67)$ reported a prior history of depression. Using the Mini international neuropsychiatric interview (M.I.N.I.), 19\% of participants $(n=37)$ had a diagnosis of Generalised Anxiety Disorder (GAD), $18 \%(n=35)$ had a diagnosis of major depressive disorder (MDD) and $10 \%$ of partici pants met criteria for minor depressive

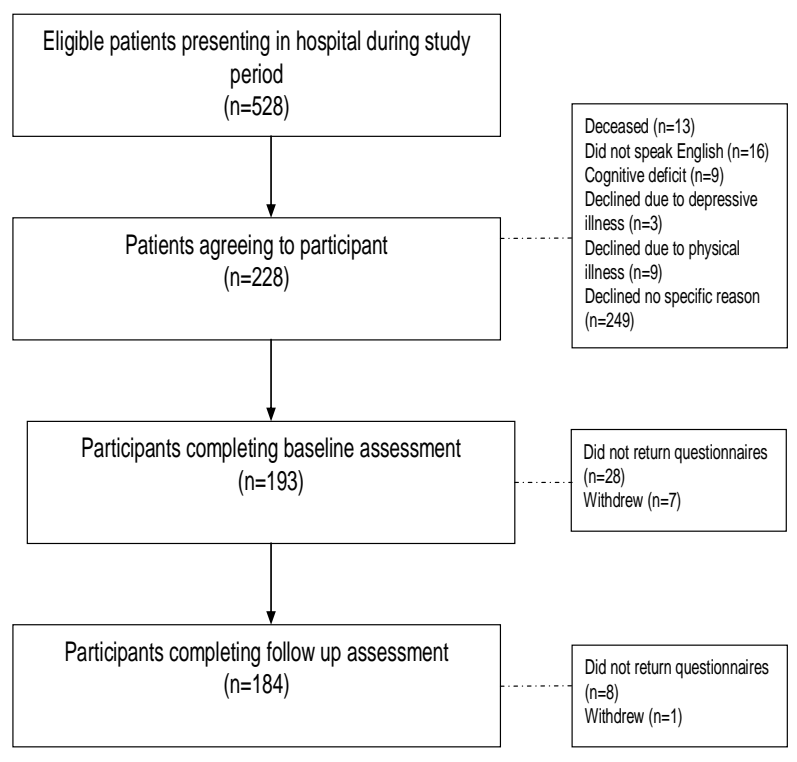

Figure 1. Flow chart for study recruitment.

disorder. Among those participants with MDD, 60\% met diagnostic criteria for GAD. Using a HADS cut-off score of $8 \%, 15 \%(n=29)$ of participants had depression. No significant differences were observed for respondents when compared with those who did not respond at follow up.

We first explored the cross-sectional relationship between baseline CSE and baseline cardiac functional status, which revealed a significant univariate association; participants with higher CSE reported significantly better functional status (Unadjusted Coef: 0.51; 0.31, 0.70). This association remained after adjustment for demographics (Model 1), medical history (Model 2), psychosocial factors (Model 3), medication use (Model 4), and clinical variables (Model 5) (data not shown). Furthermore, higher baseline CSE was significantly associated with a greater number of days in hospital (Unadjusted Coef: $0.31 ; 0.11,0.50)$; this relationship also held true when each model was applied. There was no relationship between baseline CSE and baseline LVEF.

We next explored the role of baseline CSE on six month outcomes. Univariate analyses revealed baseline CSE to be a significant predictor of cardiac functional status, six months post-CAD (Coef: 0.38; 95\% CI: 0.18, 0.58). Higher CSE scores predicted greater cardiac functioning; the magnitude of the association was consistent across all five models (Table 3). Similar trends were observed for CSE and self-rated physical health and mental health, respectively, where better CSE predicted better mental and physical health functioning in all but one model. There was no statistically significant relationship between baseline CSE scores and the likelihood of cardiac-related or other hospital admission, six months post-CAD event (Table 3). 
Table 2. Demographic characteristics of the sample $(\mathrm{N}=193)$.

\begin{tabular}{|c|c|}
\hline Variable & Mean (Standard deviation $/ 95 \%$ confidence intervals) \\
\hline Gender male & $80.08(75.22-86.43)$ \\
\hline Age in years & $64.14(10.37)$ \\
\hline Marital status Married/de facto & $75.65(18.24-30.46)$ \\
\hline Years of formal education & $10.94(3.02)$ \\
\hline Income $(<\$ 20 \mathrm{k})$ & $67.36(60.70-74.03)$ \\
\hline Diabetes & $23.32(17.30-29.33)$ \\
\hline Hypertension & $77.72(71.80-83.64)$ \\
\hline Family history of CHD & $74.09(67.86-80.33)$ \\
\hline Depression history & $34.72(27.94-41.50)$ \\
\hline Statin use & $83.07(77.67-88.46)$ \\
\hline Aspirin use & $93.20(89.59-96.80)$ \\
\hline Exertional capacity (FCS) & $24.09(6.11)$ \\
\hline Left ventricle Ejection Fraction (LVEF) (severe) & $5.70(2.4-9.00)$ \\
\hline Number of diseased arteries & $2.45(0.72)$ \\
\hline Days in hospital & $7.98(5.78)$ \\
\hline BMI $\left(\mathrm{kg} / \mathrm{m}^{2}\right)$ & $28.00(4.22)$ \\
\hline Smoking status (current smoker) & $14.00(9.05-18.92)$ \\
\hline Regular alcohol use (weekly alcohol intake) & $6.74(11.55)$ \\
\hline Depression (HADS) & $3.82(3.47)$ \\
\hline Anxiety (HADS) & $5.42(4.27)$ \\
\hline Self-rated health (PCS) & $45.32(9.60)$ \\
\hline Self-rated health (MCS) & $48.81(11.43)$ \\
\hline Social support (MSPSS) & $69.36(11.54)$ \\
\hline Neuroticism (NA) & $27.32(9.02)$ \\
\hline Cardiac self efficacy & $3.04(0.72)$ \\
\hline
\end{tabular}

Table 3. Baseline cardiac self efficacy as a predictor of adverse outcomes, 6 months post-CAD.

\begin{tabular}{|c|c|c|c|c|c|c|}
\hline Variable & $\begin{array}{l}\text { Unadjusted } \\
\text { OR \& 95\% } \\
\text { CIs }\end{array}$ & $\begin{array}{c}\text { Adjusted } \\
\text { OR (Model 1) \& } \\
95 \% \text { CIs }\end{array}$ & $\begin{array}{c}\text { Adjusted } \\
\text { OR (Model 2) \& 95\% } \\
\text { CIs }\end{array}$ & $\begin{array}{c}\text { Adjusted } \\
\text { OR (Model 3) \& 95\% } \\
\text { CIs }\end{array}$ & $\begin{array}{c}\text { Adjusted } \\
\text { OR (Model 4) \& 95\% } \\
\text { CIs }\end{array}$ & $\begin{array}{c}\text { Adjusted } \\
\text { OR (Model 5) \& 95\% } \\
\text { CIs }\end{array}$ \\
\hline $\begin{array}{l}\text { Cardiac hospital } \\
\text { admission }\end{array}$ & $\begin{array}{c}\text { OR: } 0.90 \\
(0.77-1.04)\end{array}$ & $\begin{array}{c}0.89 \\
(0.76-1.05)\end{array}$ & $0.92(0.79-1.07)$ & $0.93(0.76-1.12)$ & $0.89(0.76-1.05)$ & $0.91(0.78-1.08)$ \\
\hline $\begin{array}{l}\text { Any hospital } \\
\text { admissions }\end{array}$ & $\begin{array}{c}\text { OR: } 0.92 \\
(0.83-1.01)\end{array}$ & $\begin{array}{c}0.93 \\
(0.84-1.03)\end{array}$ & $0.93(0.84-1.03)$ & $0.98(0.87-1.11)$ & $0.92(0.83-1.01)$ & $0.93(0.84-1.03)$ \\
\hline $\begin{array}{l}\text { Cardiac Functional } \\
\text { Status (CFS) }\end{array}$ & $\begin{array}{l}\text { Coef: } 0.38 \\
(0.18-0.58)^{*}\end{array}$ & $\begin{array}{c}0.27 \\
(0.09-0.45)^{*}\end{array}$ & $0.31(0.13-0.50)^{*}$ & $0.28(0.05-0.50)^{*}$ & $0.37(0.17-0.58)^{*}$ & $0.36(0.15-0.58)^{*}$ \\
\hline $\begin{array}{c}\text { Self-rated health } \\
\text { (physical functioning) }\end{array}$ & $\begin{array}{l}\text { Coef: } 0.90 \\
(0.58-1.22)^{*}\end{array}$ & $\begin{array}{c}0.73 \\
(0.44-1.03)^{*}\end{array}$ & $0.81(0.50-1.11)^{*}$ & $0.75(0.37-1.13)^{*}$ & $0.90(0.57-1.22)^{*}$ & $0.93(0.58-1.28)^{*}$ \\
\hline
\end{tabular}

\footnotetext{
\#depression and anxiety were omitted from the model due to co linearity; ${ }^{\star}$ significant variables included social support, neuroticism.
} 
When this association was explored at 9 months post-CAD, however, higher CSE was shown to be a significant predictor of reduced odds of cardiac hospital admissions (Table 4). Univariate analysis revealed that better CSE at baseline resulted in a reduced likelihood of cardiac hospital admissions at follow up (OR: 0.84; 95\% CI: $0.73,0.97)$. When multi-variate analyses were employed, the magnitude of the association remained consistent in all but one model; the inclusion of smoking status and alcohol use in the psycho-social model (Model 3) explained away the association (OR:0.86; 95\% CI: $0.73,1.03)$. Similarly, higher CSE was shown to protect against any hospital admission at follow up (Table 4), in all but one model. Univariate analyses demonstrated that greater CSE led to a lower likelihood of hospital admissions (OR: 0.89; 95\% CI: 0.81, 0.98). However, after adjustment for HADS depression score in the psycho-social model (Model 3), this association was no longer significant (Table 4). While higher baseline CSE scores predicted cardiac functional status at 9 months, baseline HADS depression score was the strongest predictor of CFS; resulting in a significant decrease in cardiac functional status at 9 months (Adj. Coefficient: -0.44 ; 95\% CI: $-0.75,-0.12$ ) (data not shown). Baseline CSE also predicted physical and mental health functioning, nine months post CAD (Table 4). These associations were observed across all five models.

Finally, the role of CSE in cardiac- or any- hospital admission at any timepoint was explored. Univariate analyses revealed that higher baseline CSE significantly predicted reduced likelihood of any cardiac admission (OR: $0.91 ; 95 \%$ CI: $0.84,0.98$ ) or any hospital admission (OR: $0.91 ; 0.84,0.99$ )(data not shown). All associations remained significant when explored in Model 2 and 4. However, after adjustment for psychosocial variables (Model 3), none of these associations remained. HADS depression scores explained the association between baseline CSE and any cardiac admission, as well as baseline CSE and any hospital admission at 9 month follow up (data not shown).

\section{DISCUSSION}

Our findings provide some supports for cardiac self efficacy as a proxy measure for predicting subsequent cardiac functioning, and self-rated health in the months following CAD. Baseline CSE consistently predicted cardiac functioning as well as self-rated mental and physical health across all time-points. While CSE was shown to predict both general and cardiac-related hospital admissions, these relationships were explained by the presence of depression at baseline, suggesting that depression may be a stronger mediator in the relationship between self efficacy and subsequent health outcomes than previous studies suggest. For example, while data from the Heart and Soul Study have demonstrated that depression partially explains the relationship between CSE and poor health outcomes (both cross-sectionally and prospectively), both found it to be independent of depressive symptoms. While some elements of these studies are comparable (both used the same measure of CSE [23]), there may be other factors which explain differential findings. First, Sarkah (2009) explored the longer term effects of CSE on clinical outcomes of HF patients over a follow up period of 4.3 years, compared with 6 and 9 month follow up of CAD patients in the present study. It is possible that depression may mediate the association between CSE and clinical outcomes in the immediate post-coronary period when symptoms are likely to be elevated, and conversely, may not be as influential in long term prognosis, as symptoms can dissipate in the years following the event.

Table 4. Baseline cardiac self efficacy as a predictor of adverse outcomes, 9 months post-CAD event.

\begin{tabular}{|c|c|c|c|c|c|c|}
\hline Variable & $\begin{array}{l}\text { Unadjusted OR } \\
\qquad \& 95 \% \text { CIs }\end{array}$ & $\begin{array}{l}\text { Adjusted } \\
\text { OR (Model 1) } \\
\& 95 \% \text { CIs }\end{array}$ & $\begin{array}{c}\text { Adjusted } \\
\text { OR (Model 2) \& } \\
95 \% \text { CIs }\end{array}$ & $\begin{array}{c}\text { Adjusted } \\
\text { OR (Model 3) \& } \\
95 \% \text { CIs }\end{array}$ & $\begin{array}{c}\text { Adjusted } \\
\text { OR (Model 4) \& 95\% } \\
\text { CIs }\end{array}$ & $\begin{array}{c}\text { Adjusted } \\
\text { OR (Model 5) \& } \\
95 \% \text { CIs }\end{array}$ \\
\hline $\begin{array}{c}\text { Cardiac hospital } \\
\text { admission (yes/no) }\end{array}$ & $\begin{array}{c}\text { OR: } 0.84 \\
(0.73-0.97)^{*}\end{array}$ & $\begin{array}{c}\text { OR: } 0.84 \\
(0.71-0.96)^{*}\end{array}$ & $\begin{array}{c}\text { OR: } 0.84 \\
(0.73-0.98)^{*}\end{array}$ & $0.86(0.73-1.03)^{\&}$ & $\begin{array}{c}0.84 \\
(0.73-0.96)^{*}\end{array}$ & $0.83(0.72-0.97)^{*}$ \\
\hline $\begin{array}{c}\text { Any hospital } \\
\text { admissions (yes/no) }\end{array}$ & $\begin{array}{c}\text { OR: } 0.89 \\
(0.81-0.98)^{*}\end{array}$ & $\begin{array}{c}0.89 \\
(0.81-0.98)^{*}\end{array}$ & $0.89(0.81-0.98)^{*}$ & $0.90(0.81-1.01)$ & $\begin{array}{c}0.89 \\
(0.81-0.98)^{*}\end{array}$ & $0.89(0.81-0.98)^{*}$ \\
\hline $\begin{array}{l}\text { Cardiac Functional } \\
\text { Status (CFS) }\end{array}$ & $\begin{array}{l}\text { Coef: } 0.35 \\
(0.17-0.54)^{*}\end{array}$ & $\begin{array}{c}0.27 \\
(0.10-0.43)^{*}\end{array}$ & $0.31(0.14-0.48)^{*}$ & $0.29(0.08-0.51)^{*}$ & $0.34(0.15-0.53)^{*}$ & $0.37(0.17-0.57)^{*}$ \\
\hline $\begin{array}{l}\text { Self-rated health } \\
\text { (physical functioning) }\end{array}$ & $\begin{array}{l}\text { Coef: } 0.76 \\
(0.43-1.08)^{*}\end{array}$ & $\begin{array}{c}0.67 \\
(0.36-0.98)^{*}\end{array}$ & $0.67(0.36-0.98)^{*}$ & $0.62(0.24-1.00)^{*}$ & $0.074(0.41-1.07)^{*}$ & $0.76(0.41-1.10)^{*}$ \\
\hline
\end{tabular}

\#depression and anxiety were omitted from the model due to co linearity. 
There are other methodological explanations for differential findings related to the role of depression in this association. For example, different instruments were employed to measure depression. Indeed the accuracy of detecting depression in cardiac populations using these types of patient-specific self-report measures has been a topic of debate, with some arguing that cardiac-specific measures of depression are required to accurately capture depression after a coronary event. Further, it is acknowledged that the sample population in these prospective studies may not be comparable; HF patients have a particularly complex management plan compared with CAD patients which may influence their CSE and medical prognosis.

There is a growing body of evidence suggesting that depression which develops following a major coronary event represents a significant and independent risk factor for future cardiac events [24-27]. Depression following a myocardial infarction has been shown to produce a 2 to 2.5-fold increased risk for future adverse events [28]. What remains troubling is that many patients who develop depression following an acute event are not recognized during their admissions [29,30]. Proposed mechanisms for this lack of recognition include an overlap in symptomatology between the somatic symptoms of depression and those commonly found in hospitalized patients [31] or limitations in staff education and comfort in recognizing and managing depression in cardiac patients [29]. Perceived CSE has been inversely correlated with mood disorders in patients with CVD [14]. Depressed patients, who are more likely to display a lower CSE, demonstrate a longer time to return to work, poorer compliance with medication or cardiac rehabilitation regimes, and worse overall outcomes [32]. As a consequence of a lack of CSE, depressed patients can develop maladaptive coping strategies such as behavioral disengagement and avoidance [33] which may translate into a lower motivation for self care and medication adherence [34]. Given that previous studies have demonstrated that effective management of depression reduces further episodes of chest discomfort, ischemic events and use of medical resources [7], there remains a great need to recognize and treat depression when it develops in patients hospitalized for CAD.

Of further interest is the finding that at baseline, CSE score was significantly associated with greater number of days in hospital; a finding of clinical relevance. It is possible that confidence about self-management was reinforced by more comprehensive clinical advice that came with a longer hospital stay in comparison to those who were discharged sooner. Given that the average duration for hospitalization after a coronary event such as MI in Australia has been estimated to be between 2 - 5 days, there is clearly a role for the clinician in promoting self-management and thus self-efficacy. Further, while the role of depression in impairing cardiac self efficacy in this population is a topic for further investigation, identifying those with depression prior to discharge may highlight those with low self efficacy who are therefore at risk of poor clinical outcomes.

This study has several strengths. Compared with other studies that have applied a cross-sectional approach to exploring the role of self efficacy in similar populations, this study utilized a prospective design allowing us to adequately explore prospective associations between CSE and health outcomes. Further, the study yielded sound retention rates, with minimal loss to follow up which resulted in a comprehensive dataset. It should be noted however, that several significant differences in characteristics of respondents versus non-respondents were observed, pertaining to age and gender. Therefore, younger males may have been over-represented in this sample. The issue of the under-representation of women in studies of cardiac patients is well documented [35]. For example, randomized controlled trials in this area are seldom well-represented with women. Given that depression is more common in women than men (this is also true of cardiac patients), and importantly the prognosis for women post-coronary event is often poorer than their male counterparts, future studies should further explore the role of CSE in women for improving clinical outcomes.

In conclusion, this study highlights the predictive role of CSE on clinical and general health outcomes of CAD patients in the months following a coronary event. Depression was shown to explain much of this relationship; we advocate routine depression screening after a coronary event to identify those with low self efficacy and potential susceptibility to poor clinical outcomes.

\section{AUTHOR CONTRIBUTION}

LS was responsible for data collection and management. AO performed the data analysis, with contributions from LS. AO and JD were responsible for drafting the manuscript. MB and LS critically analyzed subsequent versions of the manuscript. All authors contributed to the final manuscript.

\section{DECLARATION OF CONFLICTING INTEREST}

Michael Berk has received Grant/Research Support from the NIH, Simons Foundation, CRC for Mental Health, Stanley Medical Research Institute, MBF, NHMRC, Beyond Blue, Geelong Medical Research Foundation, Bristol Myers Squibb, Eli Lilly, Glaxo SmithKline, Organon, Novartis, Mayne Pharma, Servier and Astra Zeneca. He has been a paid consultant for Astra Zeneca, Bristol 
Myers Squibb, Eli Lilly, Glaxo SmithKline, Janssen Cilag, Lundbeck and Pfizer and a paid speaker for Astra Zeneca, Bristol Myers Squibb, Eli Lilly, Glaxo SmithKline, Janssen Cilag, Lundbeck, Organon, Pfizer, Sanofi Synthelabo, Solvay and Wyeth.

\section{ACKNOWLEDGEMENTS}

The authors would like to thank Dr. Sandy Black and Dr. Morteza Mohajeri at Department of Cardiology, Barwon Health for facilitating access to patients and patient data. Dr. Stafford would like to thank Professor Henry Jackson for doctoral supervision. Dr. Stafford was supported by a scholarship from Melbourne University while conducting this study. Dr. O’Neil is supported by an Early Career Fellowship (ECF) from the National Health and Medical Research Council (NHMRC) (1052865).

\section{REFERENCES}

[1] Bandura, A. (1977) Self-efficacy: Toward a unifying theory of behavioral change. Psychological Review, 84, 191215. doi:10.1037/0033-295X.84.2.191

[2] Amagai, M., et al. (2012) Development of an instrument to measure self-efficacy for social participation of people with mental illness. Archives of Psychiatric Nursing, 26, 240-248. doi:10.1016/j.apnu.2011.09.004

[3] Berkhuysen, M.A., et al. (1999) Change in self-efficacy during cardiac rehabilitation and the role of perceived overprotectiveness. Patient Education and Counseling, 38, 21-32. doi:10.1016/S0738-3991(98)00115-3

[4] Breaux-Shropshire, T.L., et al. (2012) Relationship of blood pressure self-monitoring, medication adherence, self-efficacy, stage of change, and blood pressure control among municipal workers with hypertension. Occupational Health \& Safety, 60, 303-311. doi:10.3928/21650799-20120625-04

[5] Sarkar, U., Ali, S. and Whooley, M.A. (2009) Self-efficacy as a marker of cardiac function and predictor of heart failure hospitalization and mortality in patients with stable coronary heart disease: Findings from the Heart and Soul Study. Health Psychology, 28, 166-173. doi:10.1037/a0013146

[6] Bar-Mor, G., et al. (2000) Self-efficacy and physical activity in adolescents with trivial, mild, or moderate congenital cardiac malformations. Cardiology in the Young, 10, 561-566. doi:10.1017/S1047951100008829

[7] Gravely-Witte, S., et al. (2007) The impact of angina and cardiac history on health-related quality of life and depression in coronary heart disease patients. Chronic Illness, 3, 66-76. doi:10.1177/1742395307079192

[8] Burns, J.W. and Evon, D. (2007) Common and specific process factors in cardiac rehabilitation: Independent and interactive effects of the working alliance and self-efficacy. Health Psychology, 26, 684-692. doi:10.1037/0278-6133.26.6.684

[9] Everett, B., Salamonson, Y. and Davidson, P.M. (2009) Bandura's exercise self-efficacy scale: Validation in an
Australian cardiac rehabilitation setting. International Journal of Nursing Studies, 46, 824-829.

doi:10.1016/j.ijnurstu.2009.01.016

[10] Gardner, J.K., et al. (2003) Quality of life and self-efficacy: Gender and diagnoses considerations for management during cardiac rehabilitation. Journal of Cardiopulmonary Rehabilitation and Prevention, 23, 299-306. doi:10.1097/00008483-200307000-00007

[11] Bonsaksen, T., Lerdal, A. and Fagermoen, M.S. (2012) Factors associated with self-efficacy in persons with chronic illness. Scandinavian Journal of Psychology, 53, 333339. doi:10.1111/j.1467-9450.2012.00959.x

[12] Maeda, U., et al. (2012) Self-efficacy mediates the associations of social support and depression with treatment adherence in heart failure patients. International Journal of Behavioral Medicine, 20, 88-96.

[13] Sharp, P.B. and Salyer, J. (2012) Self-efficacy and barriers to healthy diet in cardiac rehabilitation participants and nonparticipants. Journal of Cardiovascular Nursing, 27, 253-262.

[14] Tsay, S.L. and Chao, Y.F. (2002) Effects of perceived self-efficacy and functional status on depression in patients with chronic heart failure. The Journal of Nursing Research, 10, 271-278. doi:10.1097/01.JNR.0000347608.76047.7a

[15] Cheng, T.Y. and Boey, K.W. (2002) The effectiveness of a cardiac rehabilitation program on self-efficacy and exercise tolerance. Clinical Nursing Research, 11, 10-21. doi:10.1177/105477380201100102

[16] Sarkar, U., Ali, S. and Whooley, M.A. (2007) Self-efficacy and health status in patients with coronary heart disease: Findings from the heart and soul study. Psychosomatic Medicine, 69, 306-312. doi:10.1097/PSY.0b013e3180514d57

[17] Blanchard, C.M., et al. (2002) Self-efficacy and mood in cardiac rehabilitation: Should gender be considered? Behavioral Medicine, 27, 149-160. doi: $10.1080 / 08964280209596040$

[18] Wang, J.T., Hoffman, B. andBlumenthal, J.A. (2011) Management of depression in patients with coronary heart disease: Association, mechanisms, and treatment implications for depressed cardiac patients. Expert Opinion on Pharmacotherapy, 12, 85-98. doi:10.1517/14656566.2010.513701

[19] Stafford, L., Berk, M. and Jackson, H.J. (2009) Are illness perceptions about coronary artery disease predictive of depression and quality of life outcomes? Journal of Psychosomatic Research, 66, 211-220. doi:10.1016/j.jpsychores.2008.09.005

[20] Henry, M., et al. (2000) Prevalence of osteoporosis in Australian women: Geelong osteoporosis study. Journal of Clinical Densitometry, 3, 261-268. doi:10.1385/JCD:3:3:261

[21] Barth, J., Schumaker, M. and Herrmann-Lingen, C. (2004) Depression as a risk factor for mortality in patients with coronary heart disease: A meta-analysis. Psychosomatic Medicine, 66, 802-813.

doi:10.1097/01.psy.0000146332.53619.b2 
[22] Sullivan, M.D., et al. (2001) Depression and selfreported physical health in patients with coronary disease: Mediating and moderating factors. Psychosomatic Medicine, 63, 248-256.

[23] Sullivan, M.D., et al. (1998) Self-efficacy and self-reported functional status in coronary heart disease: A sixmonth prospective study. Psychosomatic Medicine, 60, 473-478.

[24] Blumenfield, M., Suojanen, J.K. and Weiss, C. (2012) Public awareness about the connection between depression and physical health: Specifically heart disease. Psychiatric Quarterly, 83, 259-269. doi:10.1007/s11126-011-9199-6

[25] Patron, E., et al. (2012) Association between depression and heart rate variability in patients after cardiac surgery: A pilot study. Journal of Psychosomatic Research, 73, 4246. doi:10.1016/j.jpsychores.2012.04.013

[26] Steptoe, A., et al. (2012) Inflammation and symptoms of depression and anxiety in patients with acute coronary heart disease. Brain, Behavior, and Immunity, 31, 183188.

[27] Niranjan, A., et al. (2012) Depression and heart disease in US adults. General Hospital Psychiatry, 34, 254-261. doi:10.1016/j.genhosppsych.2012.01.018

[28] Vieweg, W.V., et al. (2011) Review of major measuring instruments in comorbid depression and coronary heart disease. Progress in Neuro-Psychopharmacology \& Biological Psychiatry, 35, 905-912. doi:10.1016/j.pnpbp.2011.03.009

[29] Smolderen, K.G., et al. (2011) Real-world lessons from the implementation of a depression screening protocol in acute myocardial infarction patients: Implications for the American Heart Association depression screening advisory. Circulation: Cardiovascular Quality and Outcomes, 4, 283-292. doi:10.1161/CIRCOUTCOMES.110.960013

[30] Ploux, S., et al. (2012) Depression and severe heart failure: Benefits of cardiac resynchronization therapy. Journal of Cardiovascular Electrophysiology, 23, 631-636. doi:10.1111/j.1540-8167.2011.02258.x

[31] Delisle, V.C., et al. (2012) Symptoms of heart disease or its treatment may increase Beck Depression Inventory Scores in hospitalized post-myocardial infarction patients. Journal of Psychosomatic Research, 73, 157-162. doi:10.1016/j.jpsychores.2012.07.001

[32] Nair, N., et al. (2012) Commonality between depression and heart failure. American Journal of Cardiology, 109, 768-772. doi:10.1016/j.amjcard.2011.10.039

[33] Hallas, C.N., et al. (2011) Depression and perceptions about heart failure predict quality of life in patients with advanced heart failure. Heart and Lung, 40, 111-121. doi:10.1016/j.hrtlng.2009.12.008

[34] Lossnitzer, N., et al. (2012) Incidence rates and predictors of major and minor depression in patients with heart failure. International Journal of Cardiology, 167, 502-507.

[35] O'Neil A. and Sanderson, K. (2011) Improving the identification and treatment of depression in women after acute myocardial infarction. Circulation: Cardiovascular Quality and Outcomes, 1 Pages. http://circoutcomes.ahajournals.org/cgi/eletters/4/3/283\#2 $\underline{88}$

\section{ABBREVIATIONS}

Cardiac self efficacy $=$ CSE

Cardiovascular disease $=\mathrm{CVD}$

Heart failure $=\mathrm{HF}$

Coronary artery disease $=\mathrm{CAD}$

Percutaneous transluminal coronary angioplasty $=$ PTCA

Myocardial infarction $=$ MI

Coronary artery bypass graft surgery $=\mathrm{CABG}$

Cardiac self efficacy scale $=$ CSES

Self-efficacy controlling symptoms $=$ SE-CS

Self-efficacy maintaining function $=\mathrm{SE}-\mathrm{MF}$

Left ventricular ejection fraction $=\mathrm{LVEF}$

Functional cardiac status $=$ FCS
Physical $/$ mental component summary $=$ PCS $/$ MCS

Multi-dimensional scale of perceived social support $=$ MSPSS

Body mass index $=$ BMI

Odds ratios $=\mathrm{OR}$

Standard Errors $=$ SEs

Confidence intervals $=\mathrm{CIs}$

Hospital anxiety and depression scale $=$ HADS

Mini international neuropsychiatric interview $=$ M.I.N.I.

Generalised anxiety disorder $=\mathrm{GAD}$

Major depressive disorder $=$ MDD 